\title{
Distribution of Sitting Height Ratio and its Association with Body Mass Index among Children and Adolescents in Shandong, China
}

\section{Ying-xiu Zhang*, Zun-hua Chu and Jin-shan Zhao}

Shandong Center for Disease Control and Prevention, Shandong University Institute of Preventive Medicine, Shandong, China

"Corresponding author: Ying-xiu Zhang, Shandong Center for Disease Control and Prevention, Shandong University Institute of Preventive Medicine, Jingshi Road, Jinan, Shandong-250014, China, Tel: 86-0531-82679413; Fax: 86-0531-82679413; E-mail: sdcdczyx@163.com

Received date: October 1, 2015; Accepted date: January 4, 2016; Published date: January 8, 2016

Copyright: @ 2016 Zhang YX, et al. This is an open-access article distributed under the terms of the Creative Commons Attribution License, which permits unrestricted use, distribution and reproduction in any medium, provided the original author and source are credited.

\begin{abstract}
Background: Sitting height ratio (SHR) is a useful parameter for assessing body proportion in clinical practice and other related fields. However, its association with body mass index (BMI) and obesity among children and adolescents is limited.
\end{abstract}

Methods: Data for this study were obtained from a large cross-sectional survey of schoolchildren. A total of 42 348 students ( 21248 boys and 21100 girls) aged $7-18$ years participated in this study. SHR was calculated as sitting height $(\mathrm{SH})$ divided by total height. The BMI cutoff points recommended by the International Obesity Task Force (IOTF) were used to define overweight and obesity.

Results: Children and adolescents aged $7-18$ years in the 'high SHR' group $\left(\geq 75^{\text {th }}\right)$ had higher BMI than those in the 'low SHR' group $\left(<25^{\text {th }}\right)$ in all age groups $(P<0.01)$, the range of differences being $1.28-1.55 \mathrm{~kg} / \mathrm{m}^{2} \mathrm{for}$ boys, and $1.06-1.90 \mathrm{~kg} / \mathrm{m}^{2}$ for girls. The overall prevalence of overweight and obesity were $13.40 \%$ and $4.28 \%$ for boys, and $8.11 \%$ and $1.18 \%$ for girls in the 'low SHR' group, the corresponding figures were $19.69 \%$ and $9.45 \%$ for boys, and $14.06 \%$ and $3.68 \%$ for girls in the 'high SHR' group, the latter is significantly higher than the former $(P<0.01)$

Conclusion: High SHR is associated with overweight and obesity, considering the adverse health effects of obesity, individuals with high SHR should be given special attention.

Keywords: Sitting height ratio; Body mass index; Overweight; Obesity; Child and adolescent

\section{Introduction}

Anthropological studies divided height into its components: trunk (upper body) and leg (lower body) length. In practice, sitting height (SH) used to represent trunk length and leg length was estimated by subtracting $\mathrm{SH}$ from total height. Measurement of body proportion is useful in assessing the growth and development of children and adolescents [1]. Sitting height ratio (SHR, sitting height/height $\times 100)$ is a commonly used parameter in the clinical diagnosis of disproportionate growth disorders; a larger SHR indicates relatively shorter legs for total height $[2,3]$. In this article, based on provincial data in 2010, we report the distribution of SHR and its association with obesity among children and adolescents in Shandong, China.

\section{Methods}

Data for this study were obtained from a large cross-sectional survey of schoolchildren. A total of 42,348 students $(21,248$ boys and 21,100 girls) from 16 districts in Shandong Province, students of Han nationality, aged 7-18 years, participated in the National Surveys on Chinese Students' Constitution and Health, which were carried out in September to October 2010. All subjects voluntarily joined this study with informed consents. The sampling method was stratified multistage sampling based on selected primary and secondary schools. Six public schools (two primary schools, two junior high schools and two senior high schools) from each of the 16 districts in Shandong were randomly selected and invited to participate in the study. From the selected schools, two classes in each grade were selected, and all students of the selected classes were invited to join the study.

All measurements were performed by well-trained health professionals in each of the 16 districts using the same type of apparatus and followed the same procedures. Height without shoes and $\mathrm{SH}$ were measured using metal column height/sitting height measuring stands (Yilian, TZG; Shanghai Yilian Science \& Education Equipment Company, Limited) to the nearest $0.1 \mathrm{~cm}$. The $\mathrm{SH}$ was obtained adapting a removable box $(60 \mathrm{~cm})$ to the stadiometer, where the child was sat with the trunk erect and the head in the Frankfurt plane. SHR was calculated as SH divided by total height $\times 100$. Weight was measured using lever scales to the nearest $0.1 \mathrm{~kg}$ while the subjects wore their underwear only. Body mass index (BMI) was calculated by dividing the total weight in $\mathrm{kg}$ by the total height in $\mathrm{m}^{2}\left(\mathrm{~kg} / \mathrm{m}^{2}\right)$. The BMI cutoff points recommended by the International Obesity Task Force (IOTF) were used to define overweight and obesity [4].

\section{Results}

The age- and sex-specific quartiles for SHR of children and adolescents were calculated, individuals in the upper fourth $\left(\geq 75^{\text {th }}\right)$ were defined as 'high SHR', and those in the lower fourth $\left(<25^{\text {th }}\right)$ were defined as 'low SHR', respectively. Comparisons of BMI between the two groups were made by t-test, and comparisons of overweight and obesity frequencies between the two groups were made by $\mathrm{x}^{2}$ test. All 
Citation: Zhang YX, Chu ZH, Zhao JS (2016) Distribution of Sitting Height Ratio and its Association with Body Mass Index among Children and Adolescents in Shandong, China. Biol Med (Aligarh) 8: 267. doi:10.4172/0974-8369.1000267

Page 2 of 3

analyses were performed with the statistical package SPSS/PC + version 11.5.

\begin{tabular}{|l|l|l|l|l|l|l|l|l|l|l|l|l|l|l|l|}
\hline \multirow{2}{*}{$\begin{array}{c}\text { Age/ } \\
\text { years }\end{array}$} & \multicolumn{9}{|c|}{ Boys } & \multicolumn{1}{|c|}{ Girls } \\
\cline { 2 - 14 } & $\mathrm{n}$ & Mean $\pm \mathrm{SD}$ & $15^{\text {th }}$ & $25^{\text {th }}$ & $50^{\text {th }}$ & $75^{\text {th }}$ & $85^{\text {th }}$ & $\mathrm{n}$ & Mean \pm SD & $15^{\text {th }}$ & $25^{\text {th }}$ & $50^{\text {th }}$ & $75^{\text {th }}$ & $85^{\text {th }}$ \\
\hline 7 & 1755 & $54.60 \pm 1.94$ & 53.08 & 53.7 & 54.6 & 55.46 & 55.9 & 1790 & $54.90 \pm 2.35^{*}$ & 53.3 & 54 & 55 & 56 & 56 \\
\hline 8 & 1901 & $53.77 \pm 1.82$ & 52.31 & 52.9 & 53.9 & 54.86 & 55.2 & 1819 & $53.96 \pm 1.69^{*}$ & 52.7 & 53 & 54 & 55 & 55 \\
\hline 9 & 1742 & $53.25 \pm 2.58$ & 51.82 & 52.5 & 53.4 & 54.42 & 55 & 1822 & $53.49 \pm 1.87^{*}$ & 52.1 & 53 & 54 & 54 & 55 \\
\hline 10 & 1809 & $52.87 \pm 2.41$ & 51.45 & 52.1 & 53 & 53.82 & 54.3 & 1824 & $53.19 \pm 1.97^{*}$ & 51.8 & 52 & 53 & 54 & 55 \\
\hline 11 & 1796 & $52.50 \pm 3.31$ & 51.19 & 51.8 & 52.7 & 53.74 & 54.2 & 1757 & $53.04 \pm 1.93^{*}$ & 51.7 & 52 & 53 & 54 & 55 \\
\hline 12 & 1782 & $52.26 \pm 2.04$ & 50.6 & 51.4 & 52.4 & 53.32 & 53.8 & 1721 & $53.06 \pm 2.02^{*}$ & 51.6 & 52 & 53 & 54 & 55 \\
\hline 13 & 1762 & $52.18 \pm 3.17$ & 50.71 & 51.4 & 52.3 & 53.24 & 53.8 & 1761 & $53.15 \pm 2.24^{*}$ & 51.8 & 52 & 53 & 54 & 55 \\
\hline 14 & 1672 & $52.40 \pm 2.15$ & 51.08 & 51.6 & 52.6 & 53.42 & 53.9 & 1706 & $53.39 \pm 2.04^{*}$ & 52 & 53 & 54 & 55 & 55 \\
\hline 15 & 1811 & $52.66 \pm 2.05$ & 51.17 & 51.8 & 52.8 & 53.77 & 54.3 & 1782 & $53.52 \pm 1.90^{*}$ & 52.1 & 53 & 54 & 55 & 55 \\
\hline 16 & 1718 & $52.85 \pm 1.74$ & 51.42 & 52 & 53 & 53.86 & 54.3 & 1681 & $53.56 \pm 2.51^{*}$ & 52.2 & 53 & 54 & 55 & 55 \\
\hline 17 & 1737 & $52.95 \pm 2.52$ & 51.39 & 52 & 53.2 & 54.02 & 54.5 & 1725 & $53.59 \pm 1.80^{*}$ & 52.6 & 53 & 54 & 55 & 55 \\
\hline 18 & 1763 & $53.01 \pm 2.51$ & 51.66 & 52.4 & 53.4 & 54.23 & 54.8 & 1712 & $53.61 \pm 2.92^{*}$ & 52.4 & 53 & 54 & 55 & 55 \\
\hline
\end{tabular}

Table 1: Mean, standard deviations (SD) and percentile values for SHR of Shandong Chinese children by sex and age.

*Significant difference between boys and girls $(\mathrm{p}<0.01)$.

The mean, SD and percentile values of SHR in the sample are shown in Table 1. Girls had higher SHR than boys in all age groups (7-18 years). The $50^{\text {th }}$ percentiles of SHR declined from 7 years to 11 years in girls and 13 years in boys, and then increased slightly until 18 years in both boys and girls. The $50^{\text {th }}$ percentiles of SHR changed from 54.75 in girls and 54.60 in boys, at 7 years old, to their lowest values of 53.15 in girls (aged 11 years) and 52.34 (aged 13 years) in boys, and then rose to 54.00 in girls and 53.37 in boys at 18 years old.

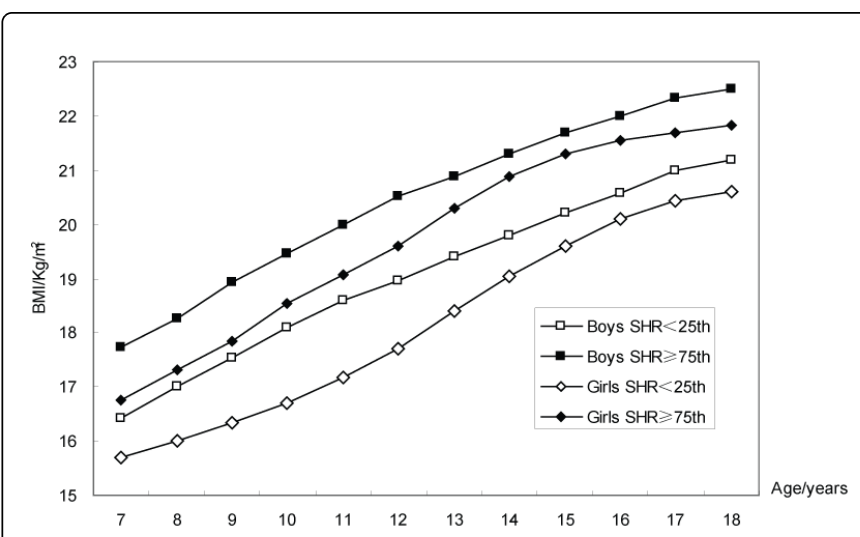

Figure 1: Mean values of BMI for boys and girls with high $\left(\geq 75^{\text {th }}\right)$ and low $\left(25^{\text {th }}\right)$ SHR.

Children and adolescents aged 7-18 years in the 'high SHR' group $\left(\geq 75^{\text {th }}\right)$ had higher BMI than those in the 'low SHR' group $\left(<25^{\text {th }}\right)$ in all age groups $(\mathrm{P}<0.01)$, the range of differences being $1.28-1.55 \mathrm{~kg} / \mathrm{m}^{2}$ for boys, and $1.06-1.90 \mathrm{~kg} / \mathrm{m}^{2}$ for girls (Figure 1).

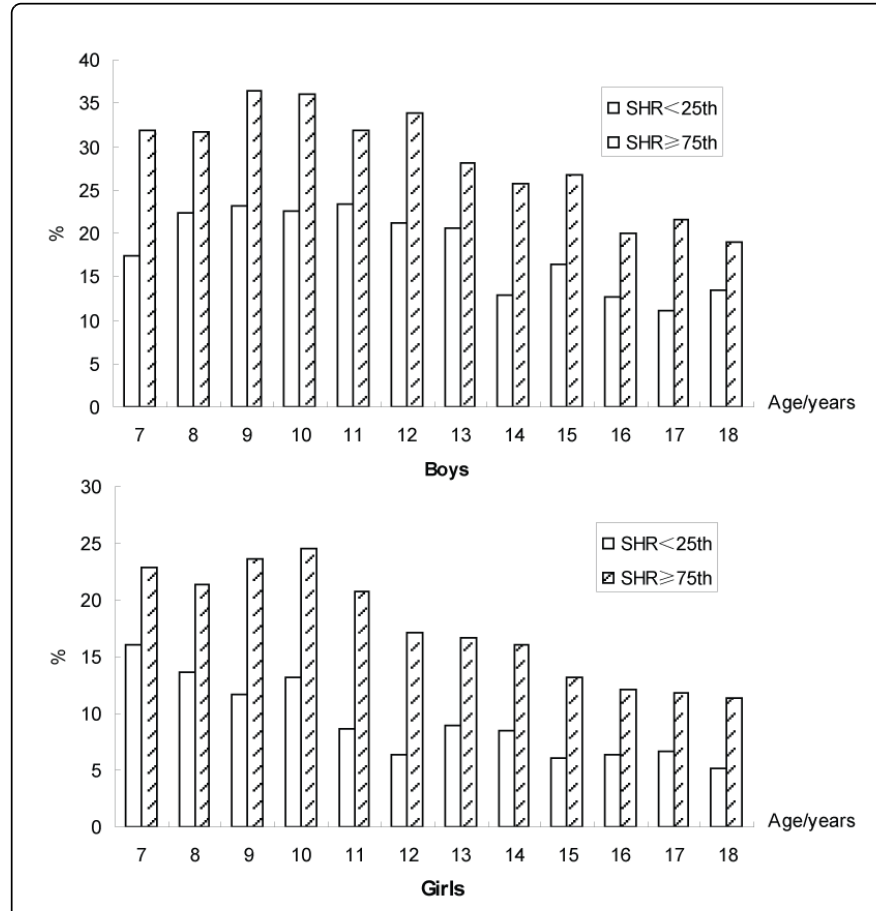

Figure 2: The prevalence of combined overweight and obesity in boys and girls with high $\left(\geq 75^{\text {th }}\right)$ and low $\left(25^{\text {th }}\right)$ SHR.

The overall prevalence of overweight and obesity were $13.40 \%$ and $4.28 \%$ for boys, and $8.11 \%$ and $1.18 \%$ for girls in the 'low SHR' group, the corresponding figures were $19.69 \%$ and $9.45 \%$ for boys, and $14.06 \%$ 
Citation: Zhang YX, Chu ZH, Zhao JS (2016) Distribution of Sitting Height Ratio and its Association with Body Mass Index among Children and Adolescents in Shandong, China. Biol Med (Aligarh) 8: 267. doi:10.4172/0974-8369.1000267

Page 3 of 3

and $3.68 \%$ for girls in the 'high SHR' group, the latter is significantly higher than the former $(\mathrm{P}<0.01)$. The prevalence of combined overweight and obesity among children and adolescents aged 7-18 years in the 'low SHR' and 'high SHR' groups are shown in Figure 2.

The prevalence of combined overweight and obesity were 11.0$23.4 \%$ for boys and $5.2-16.0 \%$ for girls in the 'low SHR' group, the corresponding figures were $19.1-36.4 \%$ for boys and $11.4-24.5 \%$ for girls in the 'high SHR' group. For both boys and girls, $\mathrm{x}^{2}$ test indicated that children and adolescents with 'high SHR' had higher prevalence of combined overweight and obesity than their peers with 'low SHR', statistical significant differences were observed in all age groups $(\mathrm{P}<0.05)$.

Prevalence of overweight and obesity among children and adolescents have been ranked as a worldwide public health concern. More importantly, increased rates of overweight and obesity, as well as associated chronic diseases, have been recently observed in many countries [5-7]. As a populous country, China has now joined the world epidemic of obesity with its rapid economic growth and urbanization [8,9]. In 2010, it was estimated that $9.9 \%$ of Chinese school-aged children and adolescents were overweight and $5.1 \%$ were obese, representing an estimated 30.43 million individuals [10]. We are facing serious challenge and should take corresponding measures to control childhood overweight and obesity. In this study, we found that SHR is associated with overweight and obesity, children and adolescents with high SHR had higher prevalence of overweight and obesity than their peers with low SHR, and should be given special attention.

\section{Conclusion}

One limitation of the present study is that the absence of detailed information concerning family environment, nutritional status, dietary patterns and physical activity at the individual level limited our study.

\section{Conflict of Interest}

There are no conflicts of interest on behalf of any of the authors.

\section{Acknowledgment}

This study was supported by the medical and health program of Shandong, China (2014WS0376). Surveys on students' constitution and health are conducted under the auspices of the department of education in Shandong Province, China. We thank all the team members and all participants. Special thanks to Mr. B Yu for providing access to the survey data.

\section{References}

1. Cheng JC, Leung SS, Lau J (1996) Anthropometric measurements and body proportions among Chinese children. Clin Orthop Relat Res 323: 22-30.

2. Marcato DG, Sampaio JD, Alves ER, Jesus JS, Fuly JT, et al. (2014) Sittingheight measures are related to body mass index and blood pressure levels in children. Arq Bras Endocrinol Metabol 58: 802-806.

3. Bogin B, Varela-Silva MI (2008) Fatness biases the use of estimated leg length as an epidemiological marker for adults in the NHANES III sample. Int J Epidemiol 37: 201-209.

4. Cole TJ, Lobstein T (2012) Extended international (IOTF) body mass index cut-offs for thinness, overweight and obesity. Pediatr Obes 7: 284-294.

5. Lobstein T, Baur L, Uauy R; IASO International Obesity TaskForce (2004) Obesity in children and young people: a crisis in public health. Obes Rev 5 Suppl 1: 4-104.

6. Wang Y, Lobstein T (2006) Worldwide trends in childhood overweight and obesity. Int J Pediatr Obes 1: 11-25.

7. Franks PW, Hanson RL, Knowler WC, Sievers ML, Bennett PH, et al. (2010) Childhood obesity, other cardiovascular risk factors, and premature death. N Engl J Med 362: 485-493.

8. Ji CY, Cheng TO (2009) Epidemic increase in overweight and obesity in Chinese children from 1985 to 2005. Int J Cardiol 132: 1-10.

9. Cheng TO (2014) China's epidemic of child obesity: an ounce of prevention is better than a pound of treatment. Int J Cardiol 172: 1-7.

10. Ji CY, Chen TJ; Working Group on Obesity in China (WGOC) (2013) Empirical changes in the prevalence of overweight and obesity among Chinese students from 1985 to 2010 and corresponding preventive strategies. Biomed Environ Sci 26: 1-12. 